\title{
JUICINESS IN CITIZEN SCIENCE COMPUTER GAMES: ANALYSIS OF A PROTOTYPICAL GAME
}

\author{
A Thesis \\ presented to \\ the Faculty of California Polytechnic State University \\ San Luis Obispo
}

\author{
In Partial Fulfillment \\ of the Requirements for the Degree \\ Master of Science in Computer Science
}

by

Eric Buckthal

June 2014 
(c) 2014

Eric Buckthal

ALL RIGHTS RESERVED 


\section{COMMITTEE MEMBERSHIP}

TITLE:

Juiciness in Citizen Science Computer

Games: Analysis of a Prototypical Game

AUTHOR: $\quad$ Eric Buckthal

DATE SUBMITTED: June 2014

COMMITTEE CHAIR: Assistant Professor Zoë Wood, Ph.D.,

Department of Computer Science

COMMITTEE MEMBER: Professor Alex Dekhtyar, Ph.D., Department of Computer Science

COMMITTEE MEMBER: Assistant Professor Foaad Khosmood, Ph.D.,

Department of Computer Science 


\begin{abstract}
Juiciness in Citizen Science Computer Games: Analysis of a Prototypical Game
\end{abstract}

Eric Buckthal

Incorporating the collective problem-solving skills of non-experts could accelerate the advancement of scientific research. Citizen science games leverage puzzles to present computationally difficult problems to players. Such games typically map the scientific problem to game mechanics and visual feed-back helps players improve their solutions. Like games for entertainment, citizen science games intend to capture and retain player attention. "Juicy" game design refers to augmented visual feedback systems that give a game personality without modifying fundamental game mechanics. A "juicy" game feels alive and polished. This thesis explores the use of "juicy" game design applied to the citizen science genre. We present the results of a user study in its effect on player motivation with a prototypical citizen science game inspired by clustering-based E. coli bacterial strain analysis. 


\section{TABLE OF CONTENTS}

List of Tables vii

List of Figures $\quad$ viii

1 Introduction 1

2 Background 3

2.1 Citizen Science . . . . . . . . . . . . . . . . . . . 3

2.1.1 Games With a Purpose . . . . . . . . . . . . . . . 3

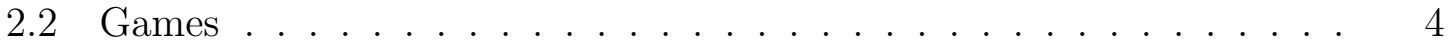

2.3 Aesthetics . . . . . . . . . . . . . . . . . 6

2.4 Game Feel . . . . . . . . . . . . . . . . . . . . . . 7

2.5 Juiciness . . . . . . . . . . . . . . . . . . . . . . . . . . 9

2.5.1 Animation .................... 11

2.5.1.1 Tweening .................. 12

2.5.2 Visual Effects . . . . . . . . . . . . . . . . 13

2.5.3 Sound Effects . . . . . . . . . . . . . . . . . . . . . 14

3 Related Works 15

3.1 Citizen science . . . . . . . . . . . . . . . . . . . . . . 15

3.1.1 Fold-it . . . . . . . . . . . . . . . . . 15

3.1.2 The Milky Way Project . . . . . . . . . . . . . . . . 17

3.1.3 Cure to Play: Genes in Space . . . . . . . . . . . . . . . . . . 18

3.2 Juiciness in Games . . . . . . . . . . . . . . . . . . . . . . . 19

3.3 E. coli Clustering . . . . . . . . . . . . . . . . . . . . 19

3.3.1 Pyroprinting. . . . . . . . . . . . . . . . . 19

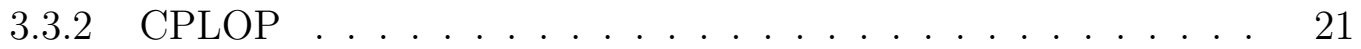

3.3.3 Strain Identification . . . . . . . . . . . . . . . . . . . . 22

3.3.4 Agglomerative Heirarchical Clustering . . . . . . . . . . . . . 22

4 Implementation 24 
4.1 Mechanics . . . . . . . . . . . . . . . . . . . . . 24

4.1.1 Modified self-similarity matrix . . . . . . . . . . . . 25

4.1 .2 Identifying strains . . . . . . . . . . . . . . . 25

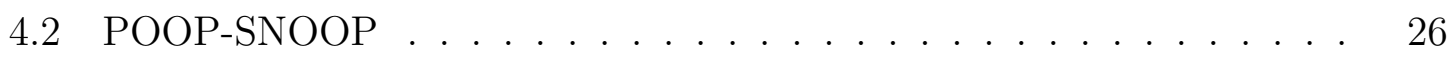

4.2 .1 The Grid . . . . . . . . . . . . . . . 26

4.2 .2 Interaction . . . . . . . . . . . . . . . . . . . 29

4.2 .3 Scoring . . . . . . . . . . . . . . . . . . . 30

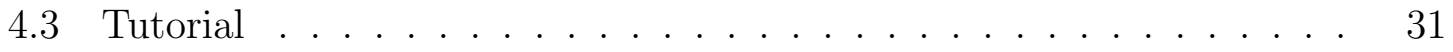

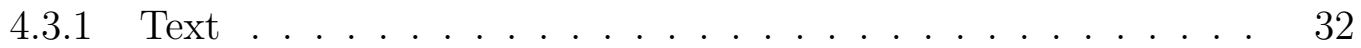

4.3 .2 Animations . . . . . . . . . . . . . . . . . . 33

5 Results 34

5.1 Experimental Setup . . . . . . . . . . . . . . . . . . . . 34

$5.1 .1 \quad$ A/B Testing . . . . . . . . . . . . . . . 34

5.1 .2 Focus Group Testing . . . . . . . . . . . . . . 35

5.2 Evaluation . . . . . . . . . . . . . . . 35

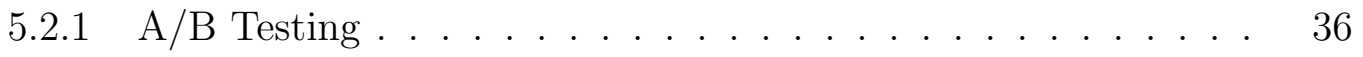

5.2 .2 Focus Group Testing . . . . . . . . . . . . . 38

6 Discussion 41

6.1 The Language of Juiciness . . . . . . . . . . . . . . . . . . . 41

6.2 Juiciness and Game Feel . . . . . . . . . . . . . . . . . . . . 42

6.2 .1 Juiciness and POOP-SNOOP . . . . . . . . . . . . 43

7 Future work 45

7.1 Long-term Engagement . . . . . . . . . . . . . . . . 46

$\begin{array}{ll}\text { Bibliography } & 47\end{array}$

$\begin{array}{ll}\text { Appendix } & 50\end{array}$ 


\section{LIST OF TABLES}

4.1 Summary of differences between "juicy" and "juiceless" POOP-SNOOP puzzle and tutorial . . . . . . . . . . . . . . . . . . . 27

5.1 Comparison of the difference in confidence and interest between players of the "juicy" and "juiceless" prototypes . . . . . . . . . . . .

5.2 Comparison of the difference in enjoyment, perceived difficulty, and understanding between players of the "juicy" and "juiceless" prototypes 38 


\section{LIST OF FIGURES}

2.1 The tight relationship between user input and system output is the foundation of great game experience . . . . . . . . . . . . . .

2.2 The correction cycle separates the levels of intent in real-time control systems . . . . . . . . . . . . . . . . . 9

2.3 Translating game feel into experiences . . . . . . . . . . . . . . 10

2.4 With one slice of Fruit Ninja, fruit sections, pulp, juice, and particles all exhibit second order motion . . . . . . . . . . . . . . . . . 11

2.5 The changing shape of the ball as it bounces creates a realistic perception of a bouncing ball, even though the animation doesnt directly emulate a bouncing ball . . . . . . . . . . . . . . .

3.1 Two sets of seven DNA sequences from unique copies of the 16S23S (green) and 23S5S (blue) ITS regions . . . . . . . . . . . .

4.1 The left image is the "juiceless" prototype. Circles indicate the current solution, black outline indicate the selected row/column pair. On the right is the "juicy" prototype with the selected row/column pair . . .

4.2 On the left, "juicy" chevrons when unselected and selected. On the right, "juiceless" chevrons when unselected and selected . . . . . . . .

4.3 On the left, the animation when completing a drag in the "juicy" prototype. On the right, the same event in the "juiceless" prototype .

4.4 On the left and right, an example of the "juicy" tutorial and "juiceless" tutorial, respectively . . . . . . . . . . . . . 


\title{
CHAPTER 1
}

\author{
Introduction
}

Though the term "gamer" still has connotations of an teenager blasting zombies in the basement, gaming has been adopted by mainstream culture [11]. Bejeweled, Candy Crush, and Farmville are only a few examples of games that have gained widespread acceptance outside of the traditional gamer persona. Computer and video games are a "form of entertainment enjoyed by a diverse, worldwide consumer base that demonstrates immense energy and enthusiasm for games." [2] 59\% of American citizens play games, the average player is 31 years old, and $48 \%$ of players are female. Puzzle, board game, game show, trivia, and card games make up $28 \%$ of online games played [2].

Leveraging the motivation to play games and humans' ability to recognize patterns, researchers have empowered users to perform citizen science. Examples of this include The Milky Way Project where users identify celestial bodies [4] and interactive biology applications such as Fold-it [7]. This partnership has introduced a more general genre of scientific discovery games which take advantage of human problem solving abilities to solve computationally difficult research problems.

Because scientific discovery games translate these research problems into games, they rely on many fundamentals of game design including the explanation of game mechanics, the design of introductory levels, and potentially the scientific concepts. More importantly, scientific discovery games' goal is to provide an interface which non-expert players can apply knowledge in a specific scientific domain. [7] While 
fun is not the primary objective, citizen science games and other genres can enhance motivation in their game by applying traditional game design strategies. Specifically, this thesis focuses on "juicy" game design techniques.

In this paper, we define "juicy" design and it's importance in the genre of citizen science games and scientific discovery games. We also explore several examples of existing scientific discovery games and their "juiciness." By prototyping and experimenting with two versions of a scientific discovery game, we conclude that "juiciness" in citizen science games decreases perceived difficulty, increases understanding of fundamental game concepts, and improves enjoyability of citizen science games. We discuss the potential for "juiciness" to improve player motivation and efficency at citizen science games. 


\title{
CHAPTER 2
}

\author{
Background
}

\subsection{Citizen Science}

A citizen scientist is "a volunteer who collects and/or processes data as part of a scientific enquiry." [23] The roots of citizen science date back to the beginnings of modern scientific exploration, where two centuries ago, science was primarily performed as a hobby [23]. With modern communication and the Internet, the number of potential citizens available to do science has grown drastically. Guidelines for scientific research still apply to citizen science projects: the data collected must be validated, the methods of collecting data must be standardized, and volunteers must receive feedback on their contribution [23].

Citizen science projects have had remarkable success in advancing scientific knowledge [5], especially in the bioscience community. These projects often fall into two categories: obtaining data to study large-scale patterns across nature [5], or using citizens ability to analyze researcher-collected data that is computationally expensive [7] [18] or simply too difficult for computers to complete accurately [4].

\subsubsection{Games With a Purpose}

There are tasks which are trivial for humans but continue to challenge sophisticated

computer programs. Traditional approaches to solving this problem focus on improving artificial intelligence systems [28]. "Games with a purpose" [28] advocate 
the constructive channeling of human brainpower through computer games. The Google Image Labeler [1] is an example of a game with a purpose where users provide meaningful labels to images on the internet, but the game is also fast-paced and competitive. Many games with a purpose avoid using computer vision techniques that do not work well and instead present players with a form of entertainment. "People play not because they are personally interested in solving an instance of a computational problem, but because they wish to be entertained." [28]

The authors presenting "games with a purpose" propose that the most important aspect of these games is that they are entertaining [28]. Even small changes and modifications of the user interface design could influence the enjoyability of these games. The primary objective of games with a purpose is to generate results, whatever they may be. In game with a purpose, throughput could be defined as the number of game objectives completed per human-hour. Games with a higher throughput should be preferred, but it is important that a game is "fun" as well [28]. No matter how efficiently players can solve a game with a purpose, "fun" is what convinces players to continue playing.

\subsection{Games}

Games are a nascent and complex medium, one which incorporates many previous forms. A single game might include painting, music, cinematography, writing and animation. If that werent enough, video games represent an unprecedented collaboration between creator and consumer. We abdicate authorial control to our players and get something. Were not quite sure what yet, but we know that it has potential. To many, interactivity seems to be the most important medium of the 21 st century. $[26]$

Video games, like the hardware they exist on, have evolved significantly since their birth. More powerful hardware have engaged players with a complex mixture of audio, video, and tactile experiences [3]. Video games are an interesting medium 


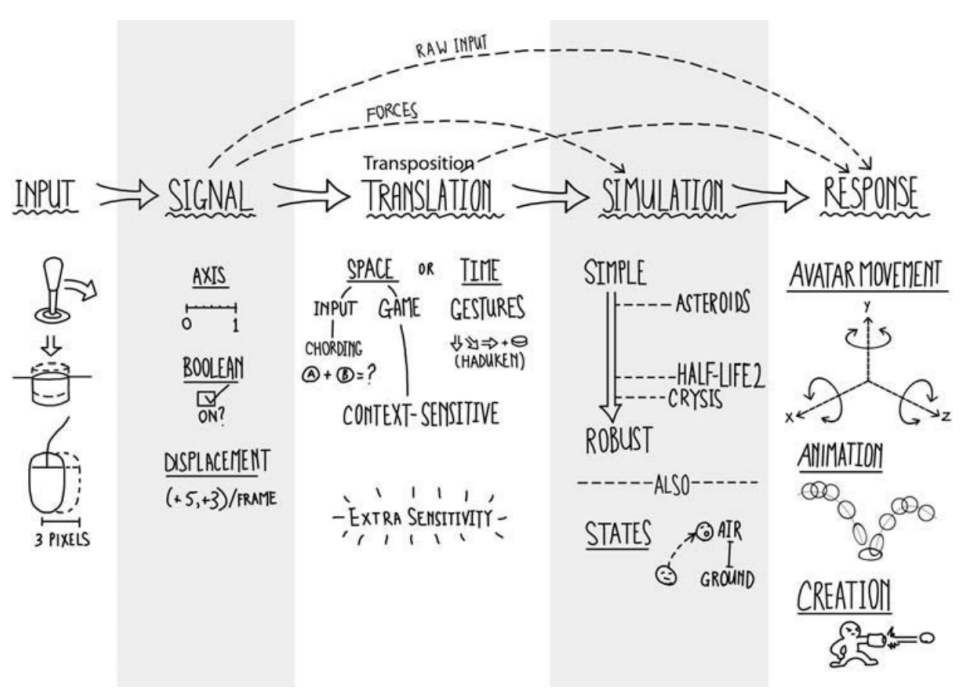

Figure 2.1: The tight relationship between user input and system output is the foundation of great game experience

of expression because they encompass so many aspects from a variety of disciplines. Artist disciplines like graphic design, animation, and sound design are expressed with more technical disciplines like computer graphics and computer science concepts. Unlike specifically broadcast mediums like radio, television, newspaper, or books, video games have an added layer of interactivity [21].

Designers of novels, television, and other linear entertainment all stress the importance of user experience [21]. Readers of novels do not influence the experience of the novel, but the novel instead controls the experience. In video games, the distinction betwen the game itself and the experience is much clearer because there is more control by the player [21]. The player can control which events happen, the pace of the events, and the randomness they may encounter. Feedback is important in games because it reinforces clues about what effects the player's input have.

While video games are interactive, it's important to note that they, like television or novels, are a tool. They are a means to an experience, Schell is very clear that the experience is completely separate from the game itself [21]. It is easy to say that 
the game is the experience because it is real and it exists. The player and game are real, but the experience is imaginary and all games are judged by the quality of this experience because it is the reason that people play games [21].

Unfortunately for designers, there is no silver bullet of design. Psychology itself focuses on the measurable, repeatable, controlled results of experimentation but treats the mind as a black box [21]. There is no objective way to design a game that exhibits a specific experience. Makers of video games (or any entertainment for that matter) can only focus on what seems to be true as opposed to what is definitely true [21].

\subsection{Aesthetics}

"Visceral design is the difference between a high aesthetic design and one that feels infused with soul." [10] Game and mobile app designers heavily depend on visceral design to create experiences that resonate with the player [10]. It's about making connections that just "feel" right. It isn't about just one design choice or mechanic, but a series of overarching interface decisions that acheives a feeling of contentment [10]. According to the authors, the key to creating visceral design is to focus on feedback loops and essential user flow mechanisms [10].

Donald Norman's seminal book, The Design of Everyday Things, proclaims that the most pleasure is attributed to extreme usability [16]. Later, in Emotional Design, Norman admits that aesthetics create an emotion as essential to the user experience as extreme usability [17].

Donald Norman breaks aesthetics into three design paradigms: visceral, behavioral, and reflective design [17]. Visceral emotions are the lowest level of emotionquick judgements that determine whether an experience is good or bad, safe or dan-

gerous. Next, the behavioral level interprets experiences as they happen, whether they are pleasurable and effective. Finally, Reflective emotion is the feeling of self- 
image and satisfaction that one perceives when remembering an experience. Visceral design can most easily be mapped to appearance, behavioral design to the pleasure and effectiveness of use, and reflective design to the self-image, personal satisfaction, or memories created [17].

These three designs directly influence human emotion and cognition, which Norman continues to describe as inseperable [17]. Aesthetically pleasing objects enable one to perform better. Scientific studies have again and again refined logical choices and explanations while very few take emotion into account [17]. Norman argues that cognition, the logical, rational side of the brain has equal importance with emotion, or how you feel, how you behave, and how you think. Norman says, "Emotion makes you smart. Emotion is always passing judgments, presenting you with immediate information about the world. Here is potential danger, there is potential comfort; this is nice, that is bad." [17] The cognitive and the affective sides of the brain work together to determine one's satisfaction of a situation. "The cognitive side interprets and makes sense of the world around you while emotions allow you to make quick decisions about it." [17]

\subsection{Game Feel}

"The aesthetic sensation of control is the starting experience of game feel." [26] This is the pure feeling of enjoying interacting with an interface and having it respond to input - the visceral design component. Experiencing game feel as skill is the process of leanring. This is why some controls feel intuitive and why some control schemes are easier to learn than others.

Game feel is positive feedback from the experience of video games [26]. Even as game designers, there is no agreed upon defintion for the language to describe game feel. A "good-feeling" game is one that let's players do what they want without 
requiring extensive throught process. "It is to video games what exists in external activities-the aethetics of driving cars, riding bikes, and so on-but nowhere is it so refined, pure, and malleable." [26]

Game feel is composed from three parts: real-time control, simulated space, and polish [26]. These "building blocks of game feel" translate interactions in to experiences. Figure 2.3 demonstrates the connections between these concepts.

Real-time control is a specific system of interactive where the player intent is transformed into action which the player interprests from the systems output. The user can then percieve the changes and formulate a new action. As players interact with a game in real-time, the correction cycle compares a users actions with the perceptions of changes in the game world. As a player intends to complete an action, they use the games controls and measure the effects to understand how to reach their goal. The correction cycle in figure 2.2 separates the levels of intent in real-time control systems [26]. Though players have a final goal of finding the princess, the correction cycle operates on the level of the avatar moving through the game world.

Simulated space refers simulated physical interactions in virtual space, perceived actively by the player [26]. These interactions give meaning and context to the motion and physicality of the objects in space. Players interacting in a simulated space feel that their actions have consequences. They are a frame of reference and gives us the tactile, physical sense of interacting with virtual environments in the same way we interact with our everyday physical spaces. When a player intends to complete an action in the game, a simulated space returns immediate feedback of their action.

Polish refers to the impacts of animations, sounds, particles, and camera shake. These important effects give clues about what type of interaction we are having with game elements and what physical characteristics they are assuming [26]. Polish is an effect which emphasize or bring clarity to the underlying simulation. Polish effects 


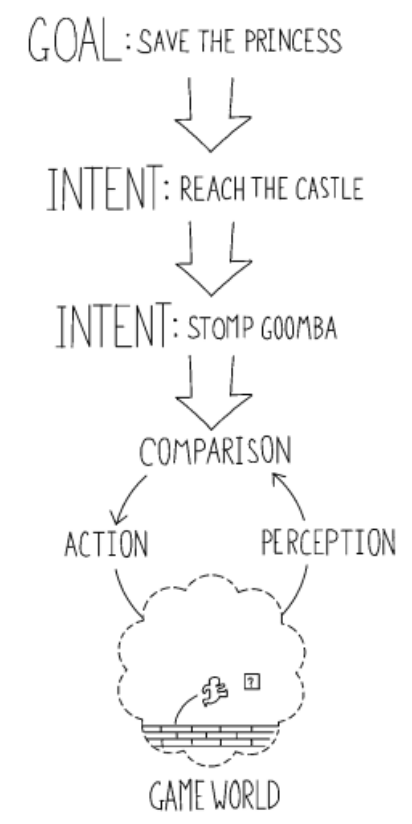

Figure 2.2: The correction cycle separates the levels of intent in real-time control systems

are only effects that artificially enchance interactions in the game without modifying the underlying simulation and control. Examples are particle effects, crashing sounds as cars collide, camera shake to emphasize a weighty impact. "This is separate from interactions such as collisions, which feed back into the underlying simulation." [26]

Many different polish effects can enhance the perception of the game interaction [26]. "Juicy" game design borrows heavily from this definition of polish.

\subsection{Juiciness}

From an influential article published in Gamasutra, "A 'juicy' game feels alive and responds to everything you do-tons of cascading action and response for minimal user input. It makes the user feel powerful and in control of the world, and it coaches them through the rules of the game by constantly letting them know on a per-interaction basis how they are doing." [12] 


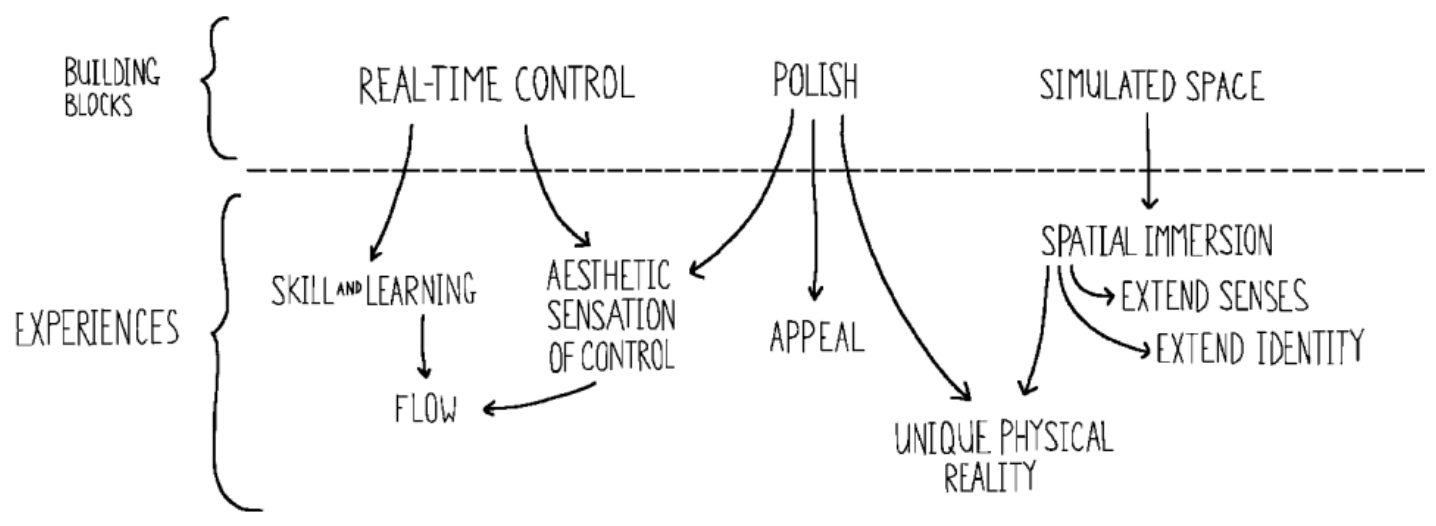

Figure 2.3: Translating game feel into experiences

The goal of "juicy" effects is to convey some property about an object or game state by offering feedback clues about how that object interacts with other objects, user input, or its environment. "Juicy" effects create the difference between a scene of a car starting from stratch and gaining speed and a car screeching and kicking up dust as it speeds away. The car may accelerate at the exact same pace in the two scenarios, but one is loaded with "juicy" effects that enhance the perception of the experience.

"Juicy" design is aesthetics as much as it is about the experience of playing. Games like Peggle and Bejeweled hark back to the audio-visual bleeps, bloops, flashes of original arcade games, and "it has to be immediate." [25] When you're doing well in a "juicy" game, you don't need to keep your eyes on the score-the game is rewarding you directly through the feedback loop. "It's not about manipulating behavior, it's about rewarding the stuff that's good for game progress." [25] A "juicy" game's appeal doesn't end if when the player reaches the end-simply experiencing the game is fun.

"Juicy systems reward the player many ways at once. When I give the player a reward, how many ways am I simutaneously rewarding them? Can I find more ways?" [21] The interface is meant to be more than just a means of communication of information, the interface should be alive, engaging, powerful, and interesting. 


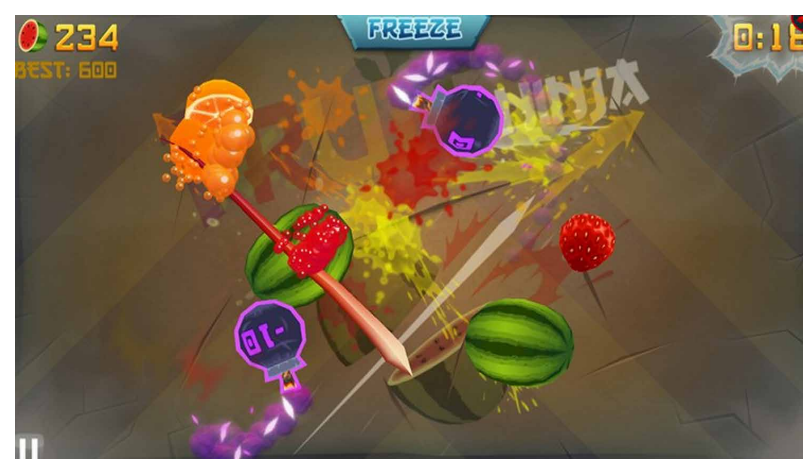

Figure 2.4: With one slice of Fruit Ninja, fruit sections, pulp, juice, and particles all exhibit second order motion

"Juicy" interfaces often exhibit plenty of second order motion; that is, motion that is derived from the action of the player." [21] When you move your finger across the touch-based "Fruit Ninja", your finger turns into the sharpest knife in the world without a visual representation of a knife. In figure 2.4, sections of fruit fly in opposite direction and fruit pulp splatters on the wall in a "juicy" display of second order motion.

The user deserves to play and explore the possibilites in the "juicy" interface whereas the "dry" interface quickly becomes a chore. "Juiciness" is the combination of satisfaction and empowerment contributing to an overall positive experience [3].

\subsubsection{Animation}

The basic "principles of animation" were developed by the original animators of Walt Disney Studio, Frank Thomas and Ollie Johnston, during the 1930s [27]. The "principles of animation" originated the widespread use of concepts like "squashing and stretching", "slow in and slow out", "exaggeration", and "appeal".

"Squashing and stretching" gives the illusion of weight and volume to a particular animated effect. It illustrates something fascinating about animation-it is much more 


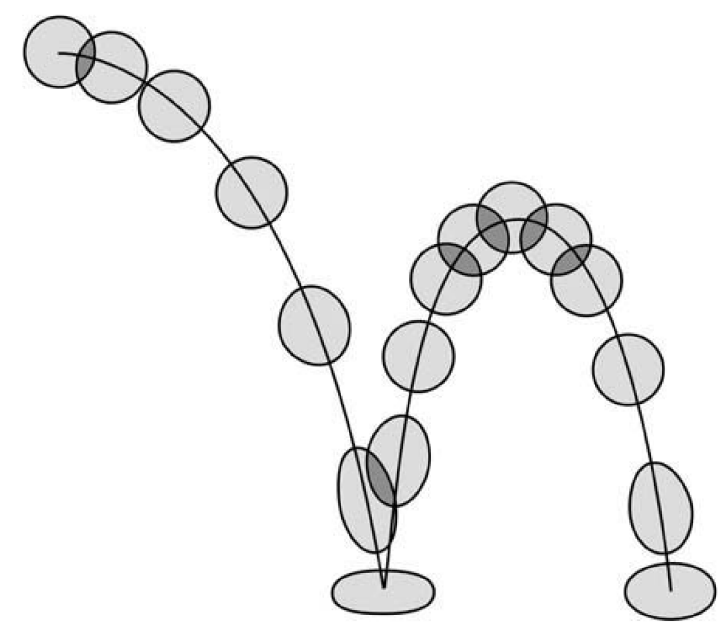

Figure 2.5: The changing shape of the ball as it bounces creates a realistic perception of a bouncing ball, even though the animation doesnt directly emulate a bouncing ball

believable to exaggerate animations rather than attempting to perfectly replicate real physical properties [26]. For example, when the bouncing ball animation reaches the ground, viewers are convinced and interested when the ball squishes to almost nothing at the bottom proceeded by stretching when the ball is mid-air. Martin Jonasson uses squashing and stretching as a subtle effect to give life to collisions and interactions in their breakout game [13].

\subsubsection{Tweening}

"Slow in and slow out" refers to a specific type of animation that attempts to model accelerations and decelleration. Short for inbetweening, "tweening" is the process of generating animation frames between two states, giving the appearence of evolution from one state to the next. The process dates back to traditional animation when the head animator would draw the keyframes and have the inbetween frames completed by their assistant. Computer animators use tweening to complete animation between 
certain desired key frames in animation, or certain states in game design. Tweening is a function of translation over time of a scalar, but vectors can be broken down into multiple scalar values [19]. As Martin Jonasson states, "you can’t always use tweening, but it's dirt easy to implement and it feels luxurious." [13] Most physical scalar values in "juicy" video games are "tweened" in some way.

In the physical world, objects infrequently changes states instantly. Whether the change be translation, rotation, colors, or opacity, tweening gives liveliness to motion and make computer elements interesting to watch. Tweening is perfect for game animation because with the quick change of a tweening function, different elements can exhibit completely transitions invoking a different emotional response to its behavior.

\subsubsection{Visual Effects}

Where animations dictate how objects move in context of their simulated space, visual effects highlight the interaction between objects [26]. Usually, visual effects appear only momentarily such as sparks flying off the bottom of a car or a crate shattering into an array of splinters. Visual effects can also be caused by an object, though it is not the animation of the object itself. Many sword fighting games employ this effect. A streak of light will follow a sword to emphasize the speed and strength of the character wielding it. In the "juicy" breakout clone by Martin Jonasson, screen flashes and shaking are used to emphasize the weight of a collision [13].

These effects encompass particle effects too. Particle effects are typically temporary indicators of movement or interaction or a specific quality of an item. Smoke and fireworks are common particle creations, and the motion of the particles is much more important than their color or shape. The motion is how players associate meaning with the particles [26]. 


\subsubsection{Sound Effects}

Sounds effects are repeatable sounds that players can associate with particular interactions in a game. Often a range of sounds will associate with an interaction to keep the players from hearing the exact same sound over and over [26]. 


\title{
CHAPTER 3
}

\author{
Related Works
}

\subsection{Citizen science}

The challenge of designing scientific discovery games is that interaction design must be optimized for suitable human interactions in the exploration process while still respecting the scientific requirements [7]. Fold-it is able to design new drugs by leveraging the creative side of humans brains to organize proteins. The game originally attracted the biochemist community, but the creator, explains during Science Friday on Public Radio International, "most biochemists quickly left the game because they were pummeled by ordinary people who had incredible spatial recognition skills." [11]

\subsubsection{Fold-it}

Fold-it coins the term scientific discovery games [7] to describe their system. Scientific discovery games are differentiated from general citizen science games because they focus on the problem solving ability of humans to solve computationaly difficult problems [7]. Fold-it incorporates many traditional aspects of game design; the highlight of Fold-it's design are the use of introductory levels to draw newcomers and explain the mechanics and the requirement that the game still be fun.

Complex graphical structures are scientifically necessary to illustrate protein structures, but they must also promote human ability to understand those complex structures [7]. The visualizations in scientific discovery games have several requirements: 
they must "reflect and illuminate the natural rules of the system" [7], "manage and hide the complexity of the system" [7], and be "approachable by players" [7] who have no knowledge of the scientific problem. They should be inviting and fun, not reminiscent of high school science textbooks. In order to make the game approachable, the protein has a bright, cartoonish feel.

The visualizations of the game are mostly cohesive, but it obvious that the aesthetics were not the priority when optimizing the players first interactions with the game. For instance the login page has an empty box which doesn't seem to contain any information, but still blocks a significant portion of my vision. There are some icons indicating my options, but they aren't necessarily carefuly chosen. The "Play Offline" icon (two computers with a do-not-enter sybmol) differs significantly from the "Play Online" button which is a smiley face.

The interactions within the puzzle are intutive and simplified. The creators of Fold-it emphasized interactions that are sufficient to explore, yet intuitive and fun [7]. Fold-it prototyped games that used sliders to indirectly manipulate the protein, but users found them unintuitive [7]. Fold-it highlights "touchability"-the feeling of grabbing and manipulating protein structures with my mouse, as opposed to rearranging sliders for the same effect [7]. Clicking and dragging with the mouse produces real-time feedback and enables the corrective cycle. While rearrange the shape of the major backbone, there are large pulsing red shapes that indicate when the structure creates physically impossible "clashes" or "voids" which warrants correction.

While the sound effects associated with Fold-it aren't particularly pleasing or reminiscent of proteins or this metaphore, they are indicitive of my current state. Sounds accompany different states including dragging and pulling certain elements or using one of the predetermined procedural "shake" or "wiggle" functions. After completing a tutorial step, a simple "Congratulations!" message flashes quickly. The 
primary motivator to complete certain shapes depends entirely on watching the score increase and decrease the shape of the protein is modified. This is intentional to "direct players towards the solution" [7] and is the only significant indicator whether some seemingly-trivial motions of the protein are good or bad for its overall structure.

Fold-it's tutorial are designed to teach non-experts by introducing concepts one level at a time. It is helpful for those who want to just jump right into the puzzles and start folding proteins. The first thing you can do in Fold-it is play with the structure of a protein and begin folding. The higher-level concepts are omitted. There are text bubbles that pop up and guide your mouse to the right tools and options.

Fold it also includes more traditional game elements to keep serious players solving puzzles. The leaderboards are noted by Cooper to be highly compettive [7].

\subsubsection{The Milky Way Project}

The Spitzer Space Telescope gathers infrared light from deep within the Milky Way [4]. Scientists have been collecting data for the last 20 years trying to understand how certain diffuse materials collect and create recurring structures and patterns. Users are shown bit-sized images of the Milky Way and provided tools to identify galaxies, star cluters, and egos. Image recognition is a common citizen science task because computationally identifying images is still a field of constant research. Fortunately, humans are surprisingly good with our eyes to make identifying irregular objects easy, but unfortunately not every person can identify each image precisely. The Milky Way project gives the same image to many people and compares the results to settle on a "correct" identification. Scientists at the University of Oxford leverage the patterns identified by "untrained" citizens to train their machine learning algorithm, Brut, which is then trained to discover "bubbles" in the Milky Way [4].

The interface itself is very simple and it is built for a simple task-identifying 
certain shapes in images. The simplicity of The Milky Way Project should not be overlooked; they have narrowed down the problem scope to an easily digestible size which makes recognition quick. The tutorial system allows users to practice on an image or automatically simulates mouse clicks that complete the tutorial for them. It is simply, but short and effective because it imitates exacty what the player will be doing in the game. There is no description of what a star cluster or a bubble represents without navigating to the "Science" page. The primary motivation to complete these tasks is simply to partake in science, though images of stars are not displeasing.

\subsubsection{Cure to Play: Genes in Space}

Genes in Space is interesting because it applies a much more traditional game atmosphere designed around abstrating out the core scientific element. The game is based on the fundamental structure of DNA chromosomes. Cancer cells exhibit certain genetic faults-changes in A, C, G, or T-that result in huge changes in parts of chromosomes known as copy number alterations. (Can the power of the public help personalise cancer treatment?) Copy number alterations can help predict the course of the disease, but it is difficult for computers to identify copy number changes. The human eye is great at detecting these shifts.

Software to identify these differences in DNA micro arrays exists, but it is unable to identify as many patterns as humans can [18]. Software has proven to take significantly identify this problem, but without results published from Genes in Space, it is impossible to compare the two methods [8].

Developers from Google, Amazon, and Facebook created the game during a weekend known as GameJam during March 2013 [18]. The DNA microarrays containing defects are translated into "routes" which your spaceship flies through to collect El- 
ement Alpha. On top of mapping your routes (the primary function of identifying copy number alterations), there are asteroids to destroy, ship upgrades to buy, and actual control of the spaceship to keep gamers entertained.

Genes in Space was conveniently developed for mobile, but over only one weekend. The weekend was focused on implementing mechanics and essential game features while the aesthetic qualities lagged. At the time of this report, the game is unplayable on iOS.

\subsection{Juiciness in Games}

Simeon Atanasov studied the effects of "juicy" design in a simple prototype, but not of the citizen science genre [3]. His conclusions site the importance of every aspect of the game; mechanics, simulated-space, and real-time control, as well as "juiciness". He claims that a player's opinion of "juiciness" can vary from the next player and that the interpretation of "juiciness" is based on the interpreted experience. He believes the biggest strenght of "juicy" design is that it "becomes a term tightly connected within a particular design, turning from a vague description to a way of keeping a

concentrated mind over what we want to achieve as designers." [3] It keeps designers focused on the parts of game design that enable good feedback channels as well as putting a natural language word on this concept.

\subsection{E. coli Clustering}

\subsubsection{Pyroprinting}

Dr. Black and Dr. Kitts of the Cal Poly Biology department have developed a library-dependent technique for comparing DNA fingerprints of bacterial isolatesspecifically the identification and classification of E. coli strains. Pyroprinting refers 


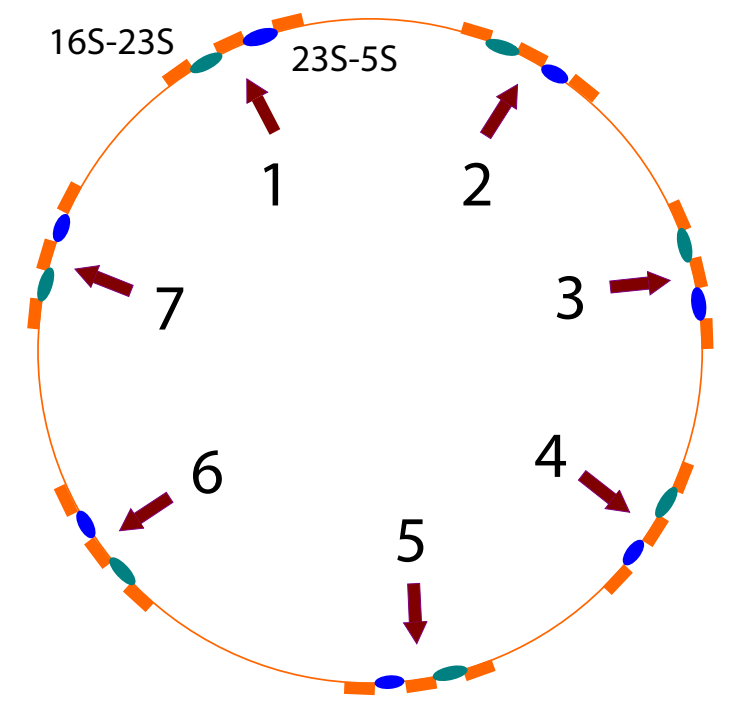

Figure 3.1: Two sets of seven DNA sequences from unique copies of the 16S23S (green) and 23S5S (blue) ITS regions

to this library-dependent method of maintaining a database of pyroprints to represent genotypic information of bacterial isolates. Each pyroprint is generated from DNA of specific, highly variable regions in a microbial genome [24] call Intergenic Transcribed Spacers (ITS). Pyroprints are generated from two ITS regions around the rRNA genes in E. coli [24]. Between the 16S and 23S genes is the ITS region 16S-23S and between the $23 \mathrm{~S}$ and $5 \mathrm{~S}$ genes is the ITS region $23 \mathrm{~S}-5 \mathrm{~S}$. There are typically seven copies of the rRNA operon in the E. coli genome and to generate a pyroprint all seven ITS loci are amplified and sequenced in a single reaction to maximix potential discrimination between strains [24]. There is variation between the $23 \mathrm{~S}-5 \mathrm{~S}$ region and the $16 \mathrm{~S}-23 \mathrm{~S}$ region in all seven loci of an E. coli sample. Pyrosequencing a single E. coli sample results in two pyroprints per isolate: one for the 16S-23S region and one for the 23S-5S region. A pyroprint is then represented as a vector of floating point values corresponding to the intensity of the reaction for each nucleotide released during the pyrosequencing reaction. Despite the relatively short sequence length from the 
pyrosequencers, the potential of discriminating between strains is maximized [24]. Pyroprints cannot be used to determine specific DNA sequences they are generated from, but rather they are a unique pattern analogous to a fingerprint of a microbe.

\subsubsection{CPLOP}

Pyroprinting is supported by a web-based database application that stores, retrieves, and analyzes isolates with their associated pyroprints as well as other relavant information, Cal Poly Library of Pyroprints (CPLOP) [24]. CPLOP is maintained by collecting samples from the environment, creating the pyroprints with pyrosequencing, managing a pyroprint library, then creating meaningful connections between samples. As the library grows to an appropriate size, unknown samples can then be compared with the database to determine their source.

MST must include a method of determining similarity between microbes. In the case of CPLOP, there must be a way to compare similarity between pyroprints. CPLOP fulfills this requirement with a Pearson correlation between two pyroprint vectors of the same region [15].

In order to perform MST with our library of pyroprints, there must be a formally defined similarity between pyroprints. Cal Poly statistics student, Diana Shealy, conducted a study to determine pyroprint comparisons into three categories: definitely similar, definitely dissimilar, and reasonably similar [22]. She defined two values $\alpha$ and $\beta$ corresponding to the threshold for similarity and dissimilarity, respectively. A Pearson correlation score between $\alpha$ and $\beta$ might mean that a pair of pyroprints are similar, but it could also mean that a false negative or false positive has occured. Diana was able to determine thresholds where the number of false negatives are $1 \%$, $5 \%$, and $10 \%$ at $0.9953,0.9941$, and 0.9915 respectively.

CPLOP [24] set the $\alpha$ and $\beta$ thresholds for CPLOP to be 0.995 and 0.99 respec- 
tively. These thresholds apply to both the 23S-5S and the 16S-23S regions.

If an isolate has several pyroprints for each ITS region, the similarity is based on a pairwise aggregation of the pyroprints for each region [24].

\subsubsection{Strain Identification}

Pyroprints represent the genotype of each ITS region and this makes pyroprints an appropriate vehicle for determining similarity in genotypes between pairs of bacterial isolates. A strain a conglomeration of similar isolates where each isolate in the strain is of some similarity to all other isolates in the strain. The task of creating strains is then determining which isolates are similar which is representative of computationally determining clusters from our dataset. The definition of a strain can fit the definition of a cluster using the Pearson correlation as a similarity metric. The interpretation of each cluster is parallel to the concept of the bacterial strain, though there is no guarantee that each cluster correlates directly to a strain. Each cluster may represent a strain or at least closely resemble one.

\subsubsection{Agglomerative Heirarchical Clustering}

Partitional clustering algorithms like K-means clustering work by developing centroids and then assigning data points based on the distance from centroids [14]. Partitional algorithms work best when there is an estimate number of clusters, but there is no estimate of number of strains when clustering begins. As new data is added to the database it becomes more dicult to estimate the number of clusters and K-means becomes less reliable. A clustering algorithm based on agglomerative hierarchical

clustering is utilized by CPLOP due to no apriori knowledge of the number of partitions [24]. In hierarchical clustering, each item starts in its own cluster. Items are groups by a similarity to other clusters by combining two clusters. The two clusters 
with the highest similarity are grouped rst, then the next more similar clusters, and soon until the items are in a single cluster. The result is a dendrogram. Items clustered earlier are more similar and items clustered later are less similar, and there is still some similarity score that connects each cluster. Hierarchical clustering solves the problem of an unknown number of clusters by allowing any threshold of similarity and the resulting clusters. 


\title{
CHAPTER 4
}

\author{
Implementation
}

The goal of POOP-SNOOP is to provide an interface that motivates non-scientist citizens to solve puzzles to further the knowledge base created by the Biology Department at Cal Poly, their work gathering and pyroprinting E. coli, and analyzing that information with various tools including CPLOP.

From the beginning, the goal was to introduce exaggerated juiciness into a citizen science game. The core mechanic of POOP-SNOOP is simple and there is plenty of room for modification many possible directions. A web browser based game was chosen to maximize possible participation; the prototypes are both created using vectorized graphics with help from a basic tweening library.

The most popular citizen science projects are hosted on Zooniverse [6], who indicate that over one million participants have helped solve science with their website although Zooniverse is a collection of dozens of games from a variety of research

projects and designers [6]. On the other hand, Fold-it requires an installation and claims 57,000 have participated [7].

\subsection{Mechanics}

The puzzle itself is very reminiscent of the spreadsheet biologists originally manipulated to visually identified strains. 


\subsubsection{Modified self-similarity matrix}

The original spreadsheet consisted of E. coli isolates organized into a self-similarity matrix of isolates in each row and column. The intersection between a row and a column compared the two isolates; a self-similarity matrix to compares a dataset to itself. To identify strains within a dataset, both the 16S-23S region and the 23S$5 \mathrm{~S}$ regions of each pyroprint. In the standard self-similarity matrix, there are two comparisons between each different member of the dataset. Each E. coli isolate must be compared on both the 16S-23S region and the 23S-5S region to be considered in the same strain, therefore by modifying the self-similarity matrix to account for these two different comparisons the modified self-similarity matrix satisfies our requirement.

Every E. coli isolate in our dataset is compared to each other dataset twiceone comparison between the 23S-5S region and one comparison between the 16S-23S region. E. coli isolates are compared to themselves once, but must be in the same strain as themselves by identity.

The self-similarity matrix must maintain the same order and length in both dimensions. An E. coli isolate is always compared to itself along the diagonal.

The comparison between two regions of DNA in an isolate is represented by a value between 0 and 1 . The threshold for strain similarity is a comparison value of 0.95 or greater, and a strain can only consist of E. coli isolates that each compare about the strain similarity threshold on both regions of compared DNA. See section 3.3.3 for more detail.

\subsubsection{Identifying strains}

Originally, identifying strains was the process of manually swapping two columns then carefully swapping the corresponding two rows to maintain the self-similarity matrix. 
Strains emerge when perfectly square clusters of DNA comparisons align along the diagonal. Metaphorically this indicates that each isolate in the indicated rows (the columns are the same isolates) could be in a strain together.

The goal of POOP-SNOOP is to encourage players to try different organizations of the puzzle to find the best possible strain. The possible solution set size is n-squared, which could be easily traversed algorithmically. This game is completely unnecessary, but an example of a potential scientific discovery puzzle game.

\subsection{POOP-SNOOP}

The essential mechanic of POOP-SNOOP is essentially reordering objects in a single dimensional list while observing their relationship with its local cluster. This data is easily represented as a spreadsheet-like grid such that players can associate with the datastructure.

Unlike many games including Fold-it [7] or Juicy Breakout [13], there isn't a specific physical metaphor for a real object that POOP-SNOOP is emulating. A spreadsheet can be thought of as a grid, or a matrix, but other than in computer applications people do not often deal with these structures. Still, in order to make this game enticing, design hints needed to be incorporated.

\subsubsection{The Grid}

Spreadsheets remind players of work and many people associate games in a completely different category than work. To incorporate the grid structure of spreadsheets without the work, the design followed a clean grid structure. Elements in the grid are the same size to represent that they are essentially representations of the same objects in our puzzle. The simulated space of POOP-SNOOP should imply a table or flat 


\begin{tabular}{|c|c|c|}
\hline Category & Juicy & Juiceless \\
\hline $\begin{array}{c}\text { Puzzle } \\
\text { initialization }\end{array}$ & Puzzle descends into place & No animation \\
\hline $\begin{array}{l}\text { Mousedown } \\
\text { row/column }\end{array}$ & $\begin{array}{l}\text { Bouncing animation, } \\
\text { simulated depth }\end{array}$ & Black outline \\
\hline $\begin{array}{l}\text { Mouseover } \\
\text { row/column }\end{array}$ & $\begin{array}{l}\text { Indicator animation } \\
\text { pointing in direction of } \\
\text { travel }\end{array}$ & Black indicator \\
\hline $\begin{array}{l}\text { Dragging } \\
\text { row/column }\end{array}$ & $\begin{array}{l}\text { Other rows slide into new } \\
\text { position }\end{array}$ & No animation \\
\hline $\begin{array}{l}\text { Mouseup } \\
\text { row/column }\end{array}$ & $\begin{array}{c}\text { Animation highlighting } \\
\text { scored cluster, background } \\
\text { effects }\end{array}$ & No animation \\
\hline Tutorial text & $\begin{array}{l}\text { Slides and fades, fonts, } \\
\text { positioning }\end{array}$ & No animation \\
\hline Tutorial slides & $\begin{array}{l}\text { Various animations per } \\
\text { slide }\end{array}$ & No animation \\
\hline
\end{tabular}

Table 4.1: Summary of differences between "juicy" and "juiceless" POOP-SNOOP puzzle and tutorial 


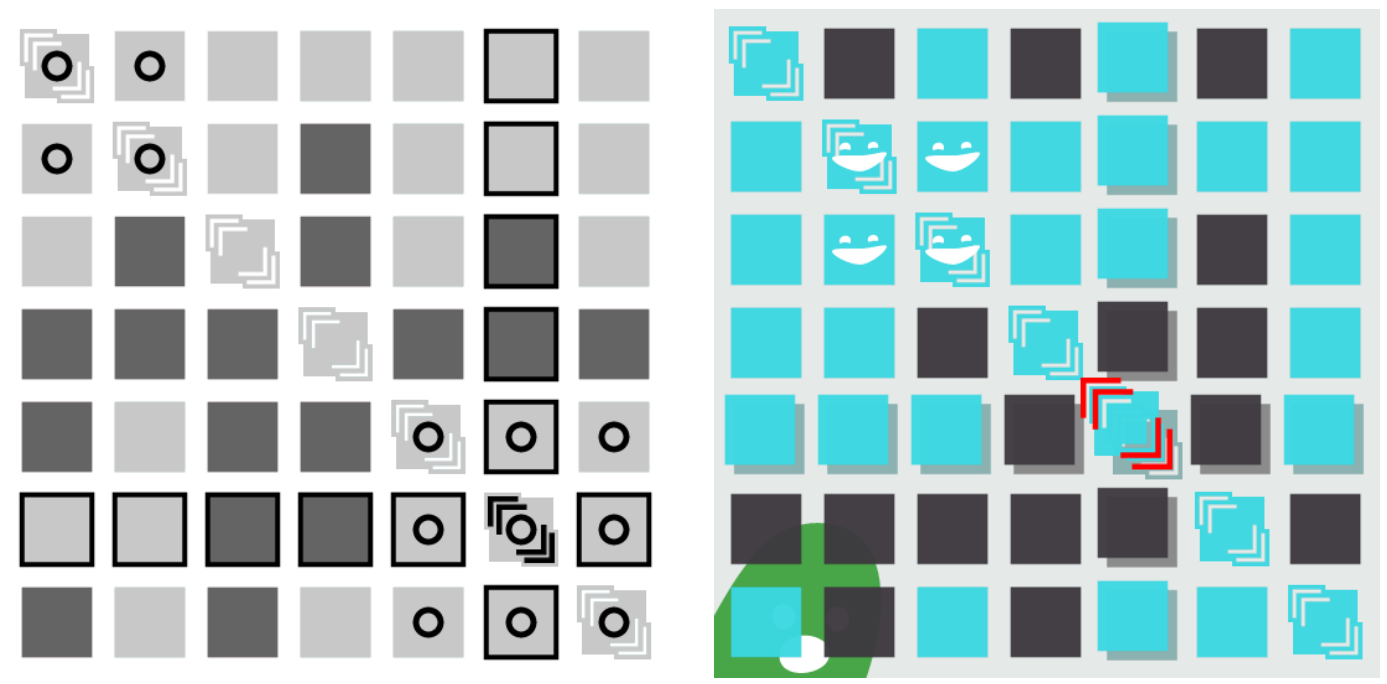

Figure 4.1: The left image is the "juiceless" prototype. Circles indicate the current solution, black outline indicate the selected row/column pair. On the right is the "juicy" prototype with the selected row/column pair

plain surface which doesn't interfere with the puzzle. In figure 4.1, each comparison between isolates is represented by a block-light gray is matching, dark gray is not matching.

Though it was originally a bit sarcastic, Petri Puhro [13] suggested personality by adding faces and adjusting their eyes to elicit emotional response. In figure 4.1, comparisons in the "juicy" prototype contributing to the solution are given a smiling face. The faces of the boxes are visible when they are part of a larger cluster. The intent is that the player would be encouraged to put as many "happy" blocks together to find the largest solution. In the non-juicy version, dark circles indicated cells that were part of a solution. 

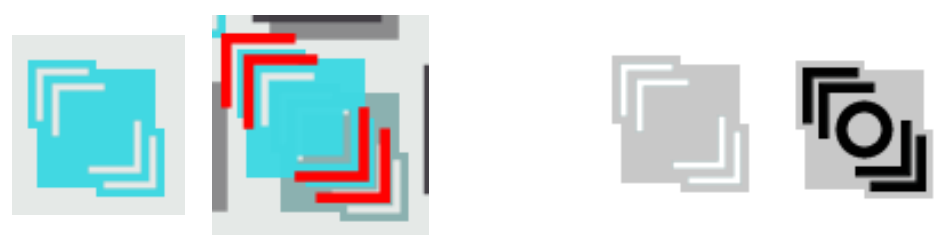

Figure 4.2: On the left, "juicy" chevrons when unselected and selected. On the right, "juiceless" chevrons when unselected and selected

\subsubsection{Interaction}

Players need to reorganize the grid easily and play with its orientation. The most fundamental metaphor for this in computer applications is clicking and dragging. If a computer user were to click an icon from the desktop and drag it, they could change its position. Unfortunately, the relationships in the grid require that the entire row and column move with it. Without explicitly connecting them in some way, the intent is that players would be able to observe the results of their action as part of the realtime feedback loop and learn the mechanic this way. As players click and drag, the grid reorganizes around them to immediately reflect the implications of their decision.

The ability to drag squares should be made obvious to players. The pieces of the grid are all important to the current and possible solutions, but only the pieces along the diagonal are interactive. To exhibit this characateristic, chevrons pointing in their potential range of travel were added. The chevrons intended to manipulate a physically rough surface or small bumps and the arrows indicated movement. In figure 4.2, the differences between the "juicy" chevron and "juiceless" chevron are demonstrated; the juicy chevron is animated.

In "juicy" POOP-SNOOP, each box has a shadow and pops up off the plane of the rest of the grid when moused over. A simple opacity and shadow gives the pieces of the puzzle depth when rows intersect slightly as players rearrange the puzzle. While 
moving the puzzle, players can see other pieces through theirs, adding to the illusion of depth. Overall, it resemebles the metaphore for small, translucent pieces of paper. The rows and cells of the grid bounce up into a hover state as they become activated which is playful, but subtle enough to not be overwhelming. As the player actively rearranges the puzzle, they are given visual hints about their actions because the rows slide gently into their new place, rather than simply appearing in their new position. Because the movement of the rows and columns is unnatural, this behavior intends to reinforce the mechanic for new players. The objects in POOP-SNOOP do not interact with eachother, but slide past one another.

As the boxes of the grid move, their motion is subtley enhanced by stretching and squeezing the direction of their movement. It is especially difficult to see how the puzzle changes when a column and row change orientation.

\subsubsection{Scoring}

Scientific discovery games exist because researchers do not know the solution to the given puzzle. Players would not normally know the solution of a POOP-SNOOP puzzle, but a message that alerted users when they solved the introductory level. In the nature of "juicy" design, the intent was that players would be given clues other than a number to indicate their score. The size of the score itself is a very visual representation of score.

Rearranging the puzzle consisted of a mousedown action to enable dragging, dragging the mouse to move the row-column pair, then releasing the mouse to return the grid to a resting state. As the player released their currently selected row, the intention of the game was to respond to that change and convey the current score to the player. Cluster highlighting happened simultaneously with background effects.

Background effects are designed reward positive player behavior with exciting 

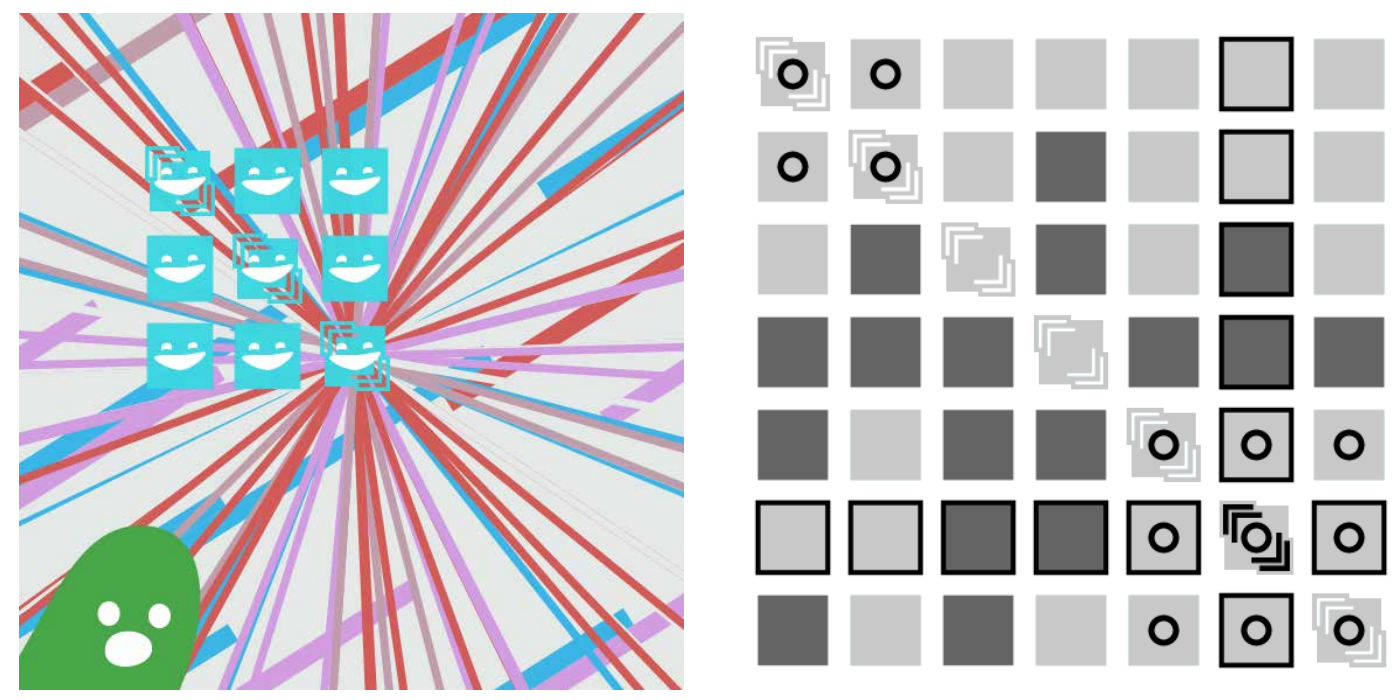

Figure 4.3: On the left, the animation when completing a drag in the "juicy" prototype. On the right, the same event in the "juiceless" prototype

explosions, colors, and motion. The goal of the effects is to encourage players to keep trying new combinations and working towards the best possible solution. The effects were designed to give more feedback for larger, better solutions and less feedback for smaller solutions. Five separated effects consisting of geometric shapes and patterns animated and exploded when dragging was complete and the score was totalled; an example of these effects can be seen in figure 4.3. The background effects lasted about two seconds and interrupted gameplay because the puzzle was hdiden. Players were able to click and end the animation early, but it was not made obvious.

\subsection{Tutorial}

POOP-SNOOP requires a tutorial. Feedback during the design phase indicated that the scientific knowledge helped players understand why they were essentially reorganizing a grid. The mechanics themselves were confusing and unintuitive to new players. Like other scientific discovery games, the tutorial is the first section of the 

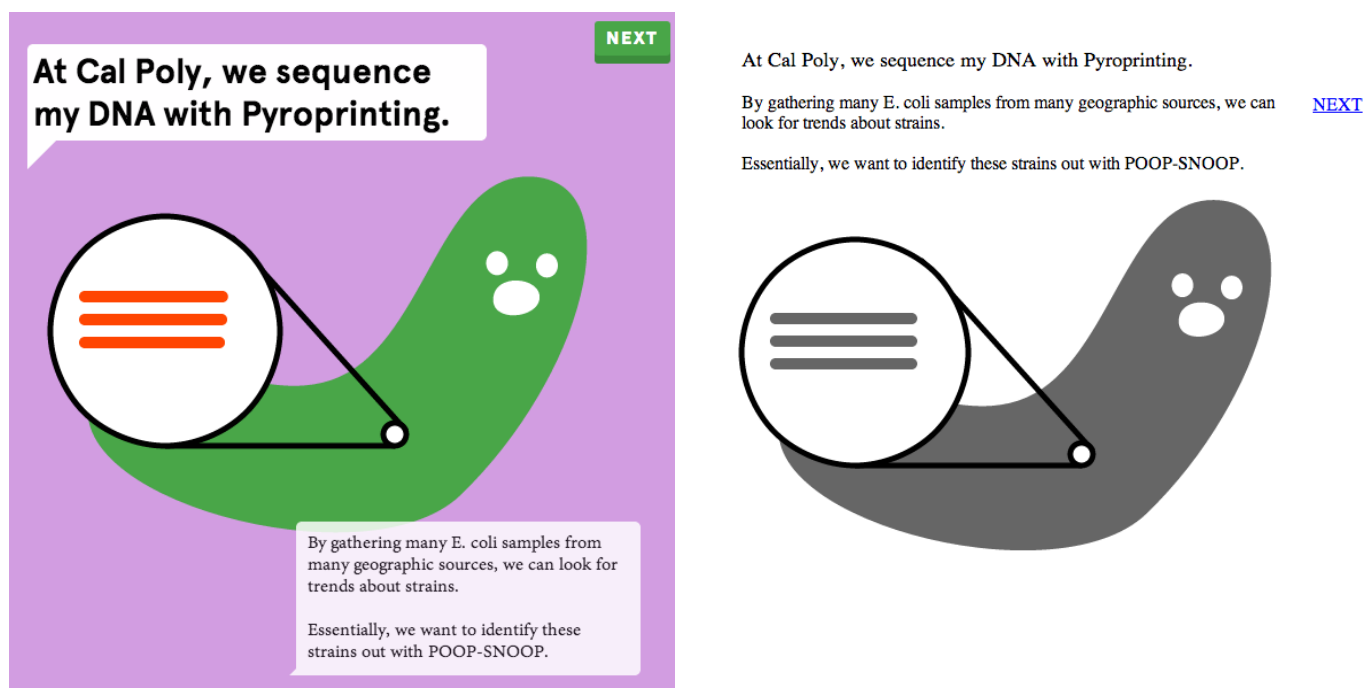

Figure 4.4: On the left and right, an example of the "juicy" tutorial and "juiceless" tutorial, respectively

game that people interact with, but does "juicy" design have implications here? Each version of POOP-SNOOP was tested with a prototypical tutorial.

The content of the tutorials was designed to be identical; each tutorial had the same illustrations, same text, and the same order. Within the tutorial, players interacted with a small version of POOP-SNOOP. The "juicy" version of the tutorial also contained the "juicy" version of POOP-SNOOP and vice versa. The "juicy" version was given some design thought. The placement of text, color, and overall feel was augmented to measure its effect on learning. One slide from both versions of the tutorial are shown in figure 4.4 .

\subsubsection{Text}

In order to entice players to read the text and digest the scientific concepts, text in the "juicy" tutorial assumed the metaphor of speech bubbles being recited by an E. coli character. The intent of this design was that players would associate the character as 
guiding them in the tutorial. Special text effects should encourage player engagement.

\subsubsection{Animations}

Both versions of the tutorial had the same content, but the "juicy" version of the puzzle would often introduce content in a more appealing way. The DNA slide "spun" into view and the lines indicating a "match" were animated and bouncing. As POOPSNOOP was introduced it gently slid down into the player's space, whereas the puzzle simply appeared in the "juiceless" version. 


\title{
CHAPTER 5
}

\author{
Results
}

\subsection{Experimental Setup}

To understand the differences between the juicy and juice-less versions of POOPSNOOP and evaluate my prototype, two experiments were executed. 88 Cal Poly undergraduate students and professors anonymously reviewed only the "juicy" version of the game while 45 students and professors anonymously reviewed only the "juice-less" version. In a separate experiment, a separate group of twelve Cal Poly students reviewed both "juicy" and "juice-less" versions of the game side-by-side while accompanied by a proctor.

The "juicy" and "juice-less" prototypes contained exactly the same text, shapes, slides, and order. The intension was to isolate juiciness, and the specific differences were identified in the Implementation Section. In the prototype, the users first completed the tutorial section which led directly into a introductory level for participants to utilize their new skills. When the puzzle had been arranged in the optimal solution, they were told that the best solution had been solved, though they were still allowed to continue playing that puzzle.

\subsubsection{A/B Testing}

To gather subjects, an opportunity to participants was presented to four classrooms of 20-30 students. More participants were only given the option to participate via 
email. All participants were given an introduction verbally or via email. The introduction briefly outlined the purpose of citizen science games, and basic instructions to complete. The essential instrutions were embedded in the game itself.

Within the game, subjects were asked to fill out a anonymous feedback form after the tutorial section and then another anonymous feedback form after playing an introductory level. The anonymous feedback forms used can be found in the appendix.

\subsubsection{Focus Group Testing}

Ten of the focus group members study a design-related subject, but none of them were involved in a computer science related field. Zero of these participants had played a citizen science game before.

Each focus group member played both versions of the prototype while being observed. They were allowed to ask questions about clarifications and encouraged to speak about their emotional response to the prototype while they played. Half of the subjects played the juiceless version first, and the second half played the juicy version first. Before the subjects were given a prototype, they were told about the nature of citizen science games some details about the origins of the data used in POOP-SNOOP. Zero participants filled out the surveys, each only provided verbal feedback.

\subsection{Evaluation}

The most significant observations from the A/B testing are:

1. Users completing the "juicy" tutorial tended to have higher confidence about solving POOP-SNOOP puzzles. 
2. Users completing the "juicy" tutorial indicated more interest continuing after the tutorial to solve POOP-SNOOP puzzles.

3. Users playing the "juicy" introductory level found their puzzle less difficult.

4. Users playing the "juicy" introductory level indicated that the tutorial was more helpful than "juiceless" players.

5. Users playing the "juicy" level indicated more enjoyment of POOP-SNOOP than "juiceless" players.

6. Frustration with fundamental game mechanics and tutorial unclarity was voiced by more "juiceless" players than "juicy" players.

7. More "juicy" prototype players specifically mentioned encouraging graphics.

From the focus group study, observations concluded:

1. The chevrons were helpful in indicating the primary mechanic in both "juicy" and "juiceless" prototypes.

2. The ideal POOP-SNOOP would be comprised of features from both the "juicy" and "juiceless" prototypes.

3. There was excessive feedback when making changes to the solution to the point that it interfered with solving the puzzle.

4. The incremental "juicy" feedback regarding different sized solutions was not effective.

\subsubsection{A/B Testing}

The two surveys given during each A/B testing session, the first after the tutorial and the second after the introductory level. The appendix lists the two surveys distributed. Table 5.1 is the summary of these qualitative results from the post-tutorial survey. Table 5.2 is the summary of quantitative results from the introductory level of POOP-SNOOP. Participants of the "juiceless" experiment completed 58 post-tutorial 


\begin{tabular}{|c|c|c|c|c|}
\hline Question & Mean Juicy & Mean Juiceless & Difference & p-value \\
\hline $\begin{array}{c}\text { How confident } \\
\text { do you feel } \\
\text { about solving a } \\
\text { POOP-SNOOP }\end{array}$ & 3.0 & 2.3 & 1.3 & 0.003 \\
puzzle? & 3.3 & 2.5 & 0.8 & $3.1 \mathrm{E}-5$ \\
How interested \\
are you in \\
solving a \\
POP-SNOOP
\end{tabular}

Table 5.1: Comparison of the difference in confidence and interest between players of the "juicy" and "juiceless" prototypes

surveys and 43 final surveys. Participants of the "juicy" experiment completed 54 post-tutorial surveys and 66 final surveys. It is not clear why there were not an equal number of surveys completed for each version of POOP-SNOOP, but without any insight into the reasons for the discrepancy none of the results were discarded.

All quantitatively measured results from the surveys were statistically significant (p-value $<0.05)$, the results are listed in Table 5.1 and Table 5.2 and summarized in the beginning of this chapter.

In the "juiceless" version, 45 of 58 responses cited confusion about game mechanics, purpose, or goal, where only 17 of 54 "juicy" participants agreed. There may be a connection between making interesting tutorial levels that increases players attention to learning the game or reading text. Players found the "juicy" version more enjoyable, and 5 of 66 responses specifically mentioned that the "juicier" graphics 


\begin{tabular}{|c|c|c|c||c|}
\hline $\begin{array}{c}\text { Question } \\
\text { Pid you enjoy }\end{array}$ & Mean Juicy & Mean Juiceless & Difference & p-value \\
\hline POP-SNOOP? & 2.0 & 2.4 & 0.6 & 0.00147 \\
\hline $\begin{array}{c}\text { Was the puzzle } \\
\text { difficult? }\end{array}$ & 2.4 & 3.5 & 1.1 & $2.8 \mathrm{E}-7$ \\
\hline $\begin{array}{c}\text { Was the tutorial } \\
\text { clear and } \\
\text { helpful? }\end{array}$ & 2.4 & 1.7 & 0.7 & 0.00045 \\
\hline
\end{tabular}

Table 5.2: Comparison of the difference in enjoyment, perceived difficulty, and understanding between players of the "juicy" and "juiceless" prototypes

were encouraging and helpful, though they had not seen the "juiceless" version.

Surprisingly, 6 of 43 "juiceless" players specifically mentioned "visually clean", "great interface", "clean presentation", or praised the visual design. Another astonishing comment from the "juiceless" survey suggested, "You need to make the game juicy" and included a link to the talk by Martin Jonasson [13] that inspired this project. Two other comments in the non-juicy version also mentioned adding color and doing more user testing. These comments were not ordinary, most comments did not mention anything about the design or the "juicy" design of POOP-SNOOP.

\subsubsection{Focus Group Testing}

In every focus group interview, each subject came to the conclusion that the ideal puzzle would contain features of both the juicy and non-juicy versions (overview result 2). When asked to make a choice about which version they would prefer to play another puzzle with, four subjects responded "juicy" and eight responded "juiceless". 
Subjects tended to prefer the non-juicy version, even if they had been given the juicy version first. Users cited the distracting "juicy" feedback interfered with their ability to solve puzzles. Users preferred the quicker response of the "juiceless" version.

Players quickly became annoyed by the overwhelming response of the system for every time they moved the puzzle orientation (overview point 3). The first time the rewarding animations happened, subjects were excited, but it became repetitive quickly.

The scoring animations were slightly more intense if the score was larger, but no subjects noticed the different between any of the animations (overview point 4). The range of possible solutions was between 2 and 4 , restricting the number of animations. There was not enough variation between the response to solutions and the response was too intense for every solution. Participants suggested that the background animation should only reward them the first time they create large solution.

The scoring animations caused player confusion when removing grid blocks that were not part of the solution. Four participants explicitly stated that they thought the puzzle was restarting or changing when the blocks dissapeared and reappared. The emphasis of the solution was inadequate; no players mentioned specifically preferring this behavior.

The chevrons for the diagonal squares were effective in both the juicy and juiceless versions (overview point 1). Early in our prototype process, the grid was simply an array of plain squares with no special markings. There was consistantly a problem with people understanding the core mechanic of POOP-SNOOP: the diagonal drag. Because the grid looked square, subjects always attempted to drag row-column pairs in any direction and simply allowing motion only in the diagonal direction never caught on. Eventually, the idea for chevrons on the diagonal was implemented and to my surprise ten out of twelve focus group participants naturally grabbed the squares 
along the diagonal and dragged them in the correct direction. The two that didn't understand the dragging motion immediately did not interact with the tutorial phases until they were forced too and seemed to skip the instruction about movement.

The lack of colors in the "juiceless" often caused confusion in the tutorial because the grays were indiscernible. More subjects interacted with the "juicy" tutorial when the puzzle first appeared on screen. The three observed participants who played with POOP-SNOOP before the introductory level started had the most success with understanding. 


\title{
CHAPTER 6
}

\author{
Discussion
}

\subsection{The Language of Juiciness}

One of the most important asepcts of designing an experiment around POOP-SNOOP is measuring "juiciness". The language of "juicy" design doesn't coincide with players vocabulary. The question, "is this game juicy?" might invoke some good guesses, but it is not perfect. Without knowledge of the difference, players would likely not discern between the experience of the game and the game itself. But again, is the game what should be measured? If games specifically create experiences, is measuring the experience the same as measuring the game?

The concept of "juiciness" is defined by the experience created while playing

the game. Atanasov [3] states that a juicy experience could be defined as plentiful "positive emotional feedback", but those words are charged with implications and may skew the results if players were asked to describe any "positive emotional feedback" they experienced during play.

While players were interviewed, they found it difficult to describe their emotional state. Instead, they verbalized their feelings about of the game. Interviewees pointed out specific aspects they liked whether the smoothness of the interface, the way the chevrons highlighted and bounced, or the flourishes of the background animations. While these emotions are aligned to a positive or negative emotion, the overall emotional response is more difficult to analyze. At which point do certain negatives 
outweight positives?

Putting POOP-SNOOP in the hemisphere of citizen science reveals a convenient definition of "positive emotional feedback". In citizen science games, players should feel motivated and encouraged to continue solving puzzles. Asking a player if they would continue playing POOP-SNOOP is not the same measurement as real citizens playing POOP-SNOOP. Because of the nature of my prototype, users were not given the ability to pursue more puzzles. We have sufficiently answered the question that with regards to citizen science games, juiciness can have a substantial impact on player attentiveness.

\subsection{Juiciness and Game Feel}

Collecting data about playing POOP-SNOOP has demonstrated that "juicy" is only part of a larger feeling of gamefulness. Like game feel suggests, mechanics play an important role in the quality of a game. Players are susceptible to juiciness' influence while learning about the mechanics of a game, as those who played the "juicy" tutorial have demonstrated, but there were still plenty of players who mentioned confusion after completing the game. Did their confusion inhibit their ability to answer the survey questions correctly? Would they have been able to answer the survey if they were confused? In this situtation, those results were utilized because there was a tendency for players of the "juicy" version to be confused less. The experiment shows those those who played the "juicy" version potentially learned the game better. The goal of "juiciness" is only to reinforce the mechanics and physicicalilty of the game, but if players cannot understand those concepts, measuring their sense of experiencing "juiciness" could potentially be misleading. 


\subsubsection{Juiciness and POOP-SNOOP}

Several aspects of playability in POOP-SNOOP potentially interfered with players' willingness to reflect on subtleties that were not playable aspects. For instance, when the introductory puzzle interrupted players with exaggerated congratulations, did they take that into account when the measured "enjoyment"? Enjoyment, interest, and difficulty are not a strictly "juicy" measurment nor is POOP-SNOOP a perfect example of "juicy" and "juiceless" design. Playability is an important fundamental in enjoyment.

Because some users of the "juiceless" version praised the clean layout, it's worth mentioning that there may have been extra "juicy" effects in the "juiceless" version. By definition, the "juiceless" version should be a version of the game that has very little visual design additions. While the earlier definition only applies to effects, particles, sounds which are all easily grouped, where does overall design fit in this model?

For instance, the design of the grid was as much part of the "juicy" version as it was in the "juicless" version. Should the "juiceless" version have incorporated less visual design, instead of just omitting the particle effects? Did incorporating a simple grid structure break the definition of "juiciness" provided or is that design fundamental to the mechanics. By measuring different versions of POOP-SNOOP, the intention was to measure the effect of design that was as extraneous as possible, but there are aspects present in both versions that could arguably be "extraneous".

Too much polish is distracting because it makes it difficult to wrap your brain around the physical sensation being conveyed [26]. The little puffs of smoke that come up as Mario slides his feet around are great because they make sense. When every single object has puffs of smoke, how does that reconcile with the experience of physical reality? Though games do not intend to perfectly replicate reality, certain 
physical sensations make more sense than others. Should "juicy" affects replicate nature? Or, is the interesting part of "juicy" effects that they are unexpected? "Juicy" design fits on this spectrum, but importantly, game designers must take care to associate effects with specific game feedback. Too many extraneous effects are just as confusing as too few.

The harmonization of polish and mechanics support the single impression of physicality [26]. In a puzzle game, physicality isn't as obvious as an immersive role-playing game. The phsyical metaphor for puzzle games are weak which potentially limits convincing "juicy" effects. 


\section{CHAPTER 7}

Future work

POOP-SNOOP had many flaws of design. To continue to study the importance of "juicy" design in citizen science applications it would be pertinent to fix problems

of understanding for the users. Instead of introducing so much science originally, the game should be modified such that players can immediately begin playing and interacting with the puzzle. When players begin POOP-SNOOP, they should learn how to solve the puzzle first, then begin to learn the science behind it, if at all. There was very little positive feedback about the scientific portion of the tutorial. Because of the difficulty people had with the tutorial, it should be modified.

Immediate feedback in POOP-SNOOP did not engage users as much as intended. Iterative design would have yieled changes in my design with respect to how the user responds to input. Though this work makes the point of important with every user input and a corresponding output. When players begin moving row/columns and adjusting the solution, there should be feedback; not only when the row/columns are released.

The implementation of "juicy" positive emotional feedback should be reassessed for future work. Users were too confused be encouraged from bombastic background animations. Work should be done iterating the scope and amount feedback users prefer.

Sound is such an important part of "juicy" design that it could be just as important as visual feedback of any kind. Sound is especially important because of users 
senstivity in that aspect as well. Well-crafted tones, effects, and background music could be unparalleled in terms of engagement, unfortunately POOP-SNOOP did not explore sound.

Even the "juiceless" version of POOP-SNOOP had positive responses to the user interface. Participants praised the "clean interface" which brings up the question: does a clean interface give the feeling of professionality and seriousness? Is that influencial in a citizen science application? POOP-SNOOP does not attempt to answer these questions.

\subsection{Long-term Engagement}

POOP-SNOOP only took the tutorial and introductory level into consideration. There is serious value in understanding "juicy" design's role in long-term engagement, especially in the field of citizen science. 


\section{BIBLIOGRAPHY}

[1] Google image labeler. http://images.google.com/imagelabeler.

[2] Essential Facts About the Computer and Video Game Industry: 2014 Sales, Demographic and Usage Data. Entertainment Software Association, 2014.

[3] S. Atanasov. Juiciness: Exploring and designing around experience of feedback in video games. Master's thesis, Malm Hgskola, 2013.

[4] C. N. Beaumont. The milky way project: Leveraging citizen science and machine learning to detect interstellar bubbles.

[5] R. Bonney. Citizen science: a developing tool for expanding science knowledge and scientific literacy. BioScience, 59(11):977-984, 2009.

[6] K. Borne. The zooniverse: A framework for knowledge discovery from citizen science data. In AGU Fall Meeting Abstracts, volume 1, page 0650, 2011.

[7] S. Cooper. The challenge of designing scientific discovery games. In Proceedings of the Fifth international Conference on the Foundations of Digital Games, pages 40-47. ACM, 2010.

[8] C. Curtis. The genomic and transcriptomic architecture of 2,000 breast tumours reveals novel subgroups. Nature, 486(7403):346-352, 2012.

[9] G. Denis and P. Jouvelot. Motivation-driven educational game design: Applying best practices to music education. In Proceedings of the 2005 ACM SIGCHI International Conference on Advances in computer entertainment technology, pages 462-465. ACM, 2005. 
[10] R. Doe. How to design for the gut. Retrieved May 17th, 2014 from https: //uxmag.com/articles/how-to-design-for-the-gut, May 2013.

[11] I. Flatow. Can we game our way to better health? Public Radio International, April 2014.

[12] P.-A. Garneau. Fourteen forms of fun. Gamasutra.com, 2001.

[13] M. Jonasson and P. Purho. Juice it or lose it. Retrieved May 1st, 2014 from https://www youtube . com/watch?v=Fy0aCDmgnxg.

[14] B. Liu. Data mining: Exploring hyperlinks, contents, and usage data. Springer, 2008.

[15] A. Montana. Algorithms for library-based microbial source tracking. Master's thesis, California Polytechnic State University, San Luis Obispo, 2013.

[16] D. A. Norman. The design of everyday things. Basic books, 2002.

[17] D. A. Norman. Emotional design: Why we love (or hate) everyday things. Basic books, 2007.

[18] J. Owens. Can the power of public help personalise cancer treatment? Retrieved May 13th, 2014 from http://scienceblog. cancerresearchuk.org/2013/03/01/ can-the-power-of-the-public-help-personalise-cancer-treatment/.

[19] R. Penner. Robert Penner's Programming Macromedia Flash MX. McGraw-Hill, Inc., 2002.

[20] D. Sargeant. Review and critique of current microbial source tracking (mst) techniques. Technical Report 11-03-038, Washington Department of Ecology, Olympia, Washington, February 2012. 
[21] J. Schell. The Art of Game Design: A book of lenses. CRC Press, 2008.

[22] D. Shealy. Exploration of pyroprinting for environmental forensics. Master's thesis, California Polytechnic State University, San Luis Obispo, 2013.

[23] J. Silvertown. A new dawn for citizen science. Trends in ecology $\mathcal{E}$ evolution, 24(9):467-471, 2009.

[24] J. L. Soliman. Cplop: The cal poly library of pyroprints. Master's thesis, California Polytechnic State University, San Luis Obispo, 2013.

[25] K. Stewart. Popcap, the 10 secrets of casual game design. Retrieved May 17th, 2014 from http://www.theguardian.com/technology/gamesblog/ 2012/aug/08/popcap-secrets-of-game-design, August 2012.

[26] S. Swink. Game Feel. Morgan Kaufmann, 2009.

[27] F. Thomas. Disney Animation: The Illusion of Life, volume 4. Abbeville Press New York, 1981.

[28] L. Von Ahn and L. Dabbish. Designing games with a purpose. Communications of the ACM, 51(8):58-67, 2008. 


\section{APPENDIX}

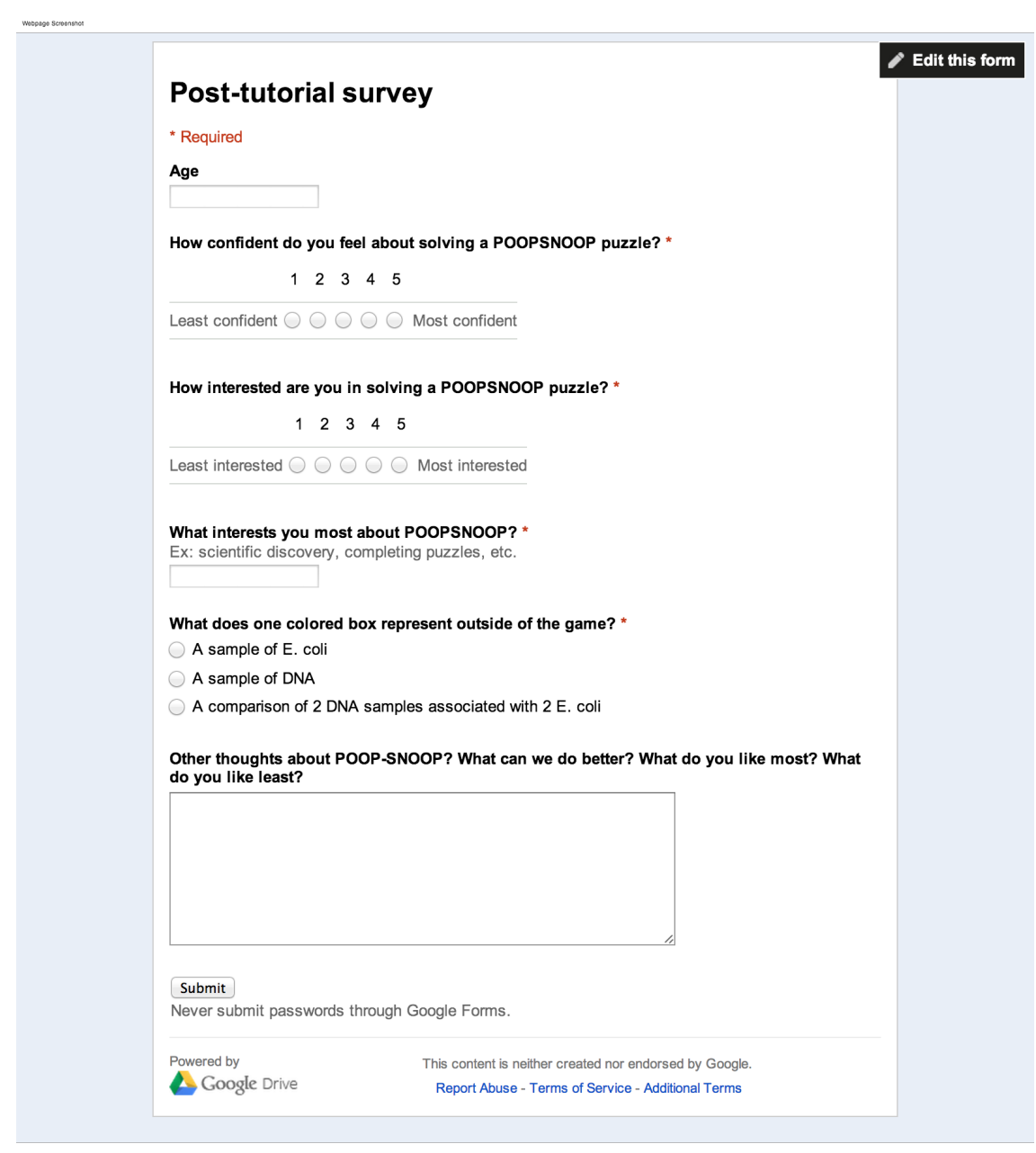

Survey given after the tutorial 


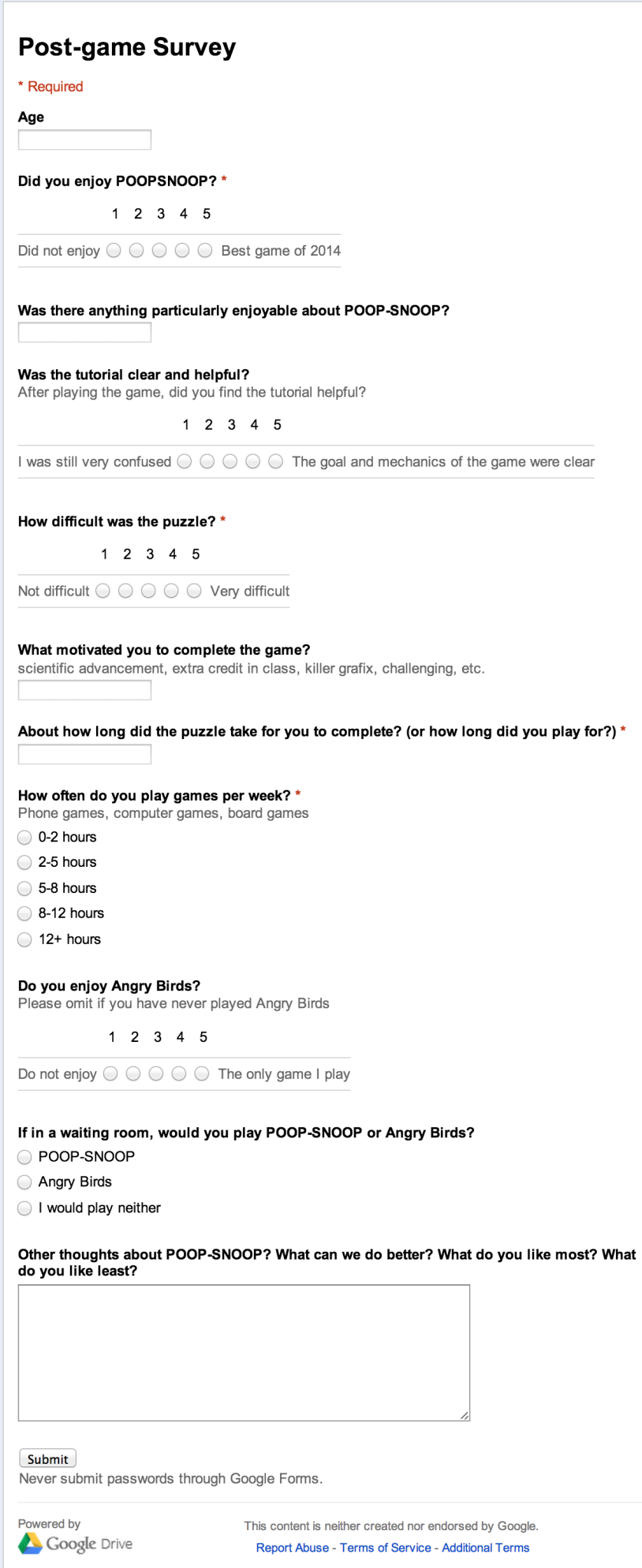

